\title{
Obstetric emergencies and non-emergencies at Central Military Hospital (I): Our vision and the epidemiologic horizon
}

\author{
Emergencias y urgencias obstétricas en el Hospital Central Militar (I): nuestra visión y \\ el horizonte epidemiológico
}

\begin{abstract}
Luis M. García-Núñez ${ }^{1 *}$, Juan A. Ramos-Martínez², Irving I. Morales-Pogoda³, Martín Fuentes-Durán ${ }^{4}$, Edgar F. Hernández-García ${ }^{5}$ and Raúl García-Ramírez ${ }^{6}$

${ }^{1}$ Critical Medicine Area; ${ }^{2}$ Emergency Department; ${ }^{3}$ Intensive Medicine Department, Critical Medicine Area. Hospital Central Militar, SEDENA; ${ }^{4}$ General Surgery, Military School for Public Health Graduates, Universidad del Ejército y Fuerza Aérea; ${ }^{5}$ Trauma Surgery Subsection, Department of Surgery; ${ }^{6}$ Sub-Directorate General. Hospital Central Militar, SEDENA. Mexico City, Mexico
\end{abstract}

\begin{abstract}
Background: Maternal morbidity and mortality pose a significant impact on national public health, being medical attention of obstetric emergencies (OE) and non-emergencies (ONE) of capital importance. Methods: Descriptive and epidemiologic analysis of OE/ONE at a 3rd level military echelon. Results: During a 34-months span, 48 patients were approached at the emergency department (1.4 admissions/month). Mean age: $29 \pm 3$ years (17-41). Eight patients (17\%) were considered OE and 40 (83\%) ONE. Fifty-eight percent $(n=28)$ of patients were admitted to our institution; $32 \%(n=9)$ were managed under non-surgically basis and $68 \%(n=19)$ underwent surgical therapy. Most important cause of admission: postoperative hemorrhage (22\%; $n=6)$. Most frequent operative interventions: surgical hemostasis maneuvers $(31.5 \% ; n=6)$. Eighty-two percent $(n=23)$ of admissions required management at intensive care unit (ICU), with mean length of stay of 6.4 \pm 4.9 days (2-21). Thirty-five percent $(n=8)$ required mechanical ventilation. Mean score of APACHE II at ICU: $19.4 \pm 8.4$; predicted probability of death: 35.5\%. Global morbidity rate: 27\% (1.8 complications/patient). Global mortality rate: $6.2 \%$; specific mortality for pregnant patients $0 \%(n=0)$ and for post-partum patients $12.5 \%(n=3)$. Mortality rate at ICU: $4.3 \%(n=1)$. Conclusions: Central Military Hospital has delineated and defined several procedures to decrease maternal morbidity and mortality. Appropriate practice of these procedures contributes to reach the desired institutional objectives.
\end{abstract}

KEY WORDS: Maternal mortality. Obstetric emergency. Maternal morbidity.

\section{Resumen}

Introducción: La morbimortalidad materna posee un significativo impacto en la salud pública nacional, siendo la atención médica de las emergencias obstétricas (EO) y urgencias obstétricas (UO) de capital importancia. Método: Análisis descriptivo y epidemiológico de EO/UO en un escalón militar de tercer nivel. Resultados: Durante 34 meses se abordaron en el departamento de urgencias 48 pacientes (1.4 admisiones/mes). La edad media fue de $29 \pm 3$ años (rango: 17-41). Ocho pacientes (17\%) se consideraron EO y 40 (83\%) UO. El 58\% $(n=28)$ de las pacientes se admitieron a la institución; el 32\% $(n=9)$ se manejaron médicamente y el $68 \%(n=19)$ con tratamiento quirúrgico. La causa más importante de admisión fue la hemorragia posoperatoria $(22 \% ; n=6)$. Las intervenciones quirúrgicas más frecuentes fueron maniobras de hemostasia quirúrgica (31.5\%; $n=6)$. El $82 \%(n=23)$ de las admisiones requirieron manejo en la unidad de medicina intensiva (UMI), con una estancia media de $6.4 \pm 4.9$ días (rango: 2-21). El 35\% $(n=8)$ requirieron ventilación mecánica. La puntuación me-

\author{
Correspondence: \\ *Luis Manuel García-Núñez \\ Av. Ejército Nacional y Blvd. \\ Manuel Ávila Camacho, s/n \\ Col. Lomas de Sotelo, Del. Miguel Hidalgo \\ C.P. 11200, Ciudad de México, México \\ E-mail: Imgarcian@ hotmail.com
}

Date of reception: 15-01-2017

Date of acceptance: 08-04-2018

DOI: 10.24875/CIRUE.M18000023
Cir Cir. 2018;86:143-150

Contents available at PubMed www.cirugiaycirujanos.com 
dia APACHE II en la UMI fue de $19.4 \pm 8.4$, y la probabilidad predicha de muerte fue del $35.5 \%$. La tasa global de morbilidad fue del 27\% (1.8 complicaciones/paciente). La tasa de mortalidad global fue del 6.2\%; la mortalidad específica para pacientes embarazadas del $0 \%(n=0)$ y para pacientes puérperas del $12.5 \%(n=3)$. La tasa de mortalidad en la UMI fue del $4.3 \%$ $(n=1)$. Conclusiones: El Hospital Central Militar ha delineado y definido diversos procedimientos para abatir la morbimortalidad maternas. La correcta práctica de estos procedimientos contribuirá a alcanzar los objetivos institucionales deseados.

PALABRAS CLAVE: Mortalidad materna. Emergencia obstétrica. Morbilidad materna.

\section{Introduction}

Maternal mortality (defined as the death of a woman during pregnancy or within 42 days after its termination, regardless of the duration and place of pregnancy, due to causes directly related to pregnancy and its effects, obstetric conditions, or preexisting diseases or diseases evolving during pregnancy, not due to obstetric causes, but worsened by the state of gestation) is a sensitive index of a national emergency, since its high rate reveals inequity, lack of access to health services and deficient quality in obstetric care ${ }^{1}$. In Mexico, unfortunately, it prevails as a serious epidemiological problem and constitutes a huge challenge for public and private health authorities ${ }^{2}$.

According to figures of the World Health Organization, in 2015 there were around 303,000 deaths in the world due to complications of pregnancy or puerperium. Most deaths occurred in countries with low socio-political development and are related, without a doubt, to low economic income. In Mexico, the most recent and reliable statistics date back to 2014 (Ministry of Health) and the figures are truly alarming: in that year, 872 maternal deaths were recorded (2.3 per day), with $71 \%$ of them occurring only in 12 states. However, it is notable that the maternal death ratio (MDR) has decreased from 1990 to date (MDR 89 versus MDR 38.9), which reflects the compliance with the Sustainable Development Goals defined by the Federal Government, with a general tendency towards a reduction in maternal mortality in the nation ${ }^{1-4}$.

Administrative and assistance policies that since 2012 prevail and are observed at the Central Military Hospital clearly show the high level of importance maternal mortality and morbidity represent for the institution. Owing to this, the critical medicine area and its subordinate departments developed the first one of three phases of obstetric emergency and non-emergency care analysis in the institution (epidemiological phase, proposal of protocols and design of protocols). In this first phase, an epidemiological profile of those patients who arrive with the operative definition of "obstetric emergency" (OE) or "obstetric non-emergency" (ONE) will be outlined (Table 1) ${ }^{1}$.

Descriptive and analytical statistics were applied to identify significant risk factors for the increase in morbidity and mortality, with the incidence of the disease in our population being determined. Disease prognosis was studied by analyzing the indicators used to measure severity in different areas of approach, as well as their use to define patient definitive treatment, evaluating the efficacy of the medical and surgical treatment applied in our institution with a simple and standardized approach in order to generate, analyze and disseminate information and being able to compare our results with those the world literature points at, which are facts of high relevance for health policies to be formulated ${ }^{1-4}$.

Finally, the study intends to contribute to the design and validation of medical-surgical approach protocols for patients with OE and ONE, which will allow the use of human, material and administrative resources to be improved, as well as to identify the right moment to apply each one of them, and thereby optimize survival and functionality indexes and decrease the rate of disabling complications, thus raising the quality of medical care and promoting social well-being ${ }^{1-4}$.

\section{Method}

A review of the electronic and physical health records of the Central Military Hospital was carried out within a 34-month period (from January 2015 to October 2017), in order to detect the records of patients who met the operational definitions of OE and ONE. From the total number of patients admitted to the emergency department of our institution ( $N=1190)$, $48(4 \%)$ meeting the criteria to be included in this analysis were identified.

Since human and material resources for obstetric-gynecological and pediatric care are outside our hospital (Hospital Militar de Especialidades de la Mujer y Neonatología, HMEMYN), all patients of our population (active army members and beneficiaries who 
Table 1. Operational definitions for the Central Military Hospital

\begin{tabular}{|c|c|}
\hline Variable & Operational definition \\
\hline Pregnancy & Period comprised from the conception to the expulsion or extraction of the fetus and its annexes. \\
\hline Puerperium & $\begin{array}{l}\text { Period that follows the expulsion of the pregnancy product, where anatomophysiological changes of } \\
\text { pregnancy are reverted. It lasts } 6 \text { weeks or } 42 \text { days, and it is divided into: } \\
\text { Immediate: includes the first } 24 \text { hours after delivery. } \\
\text { Early: is the period that covers from the second to the seventh day after delivery. } \\
\text { Remote: is the period that includes from day } 8 \text { to } 42 \text { after delivery. }\end{array}$ \\
\hline Obstetric emergency (OE) & $\begin{array}{l}\text { State that puts the life of the mother or of the product of gestation in danger during the gravid-puerperal } \\
\text { stage, which requires immediate medical or surgical care by qualified medical personnel. }\end{array}$ \\
\hline Obstetric non-emergency (ONE) & $\begin{array}{l}\text { Medical complication during gestation, delivery or puerperium, which increases the risk of maternal and } \\
\text { perinatal morbidity or mortality. }\end{array}$ \\
\hline Obstetric triage & $\begin{array}{l}\text { First-contact OE care protocol, which aims to classify the situation of severity of patients and specify the } \\
\text { action necessary to preserve the mother-child binomial life or an organ viability within a therapeutic period. } \\
\text { The system has been adapted to be used in the perinatal period (pregnancy, delivery and puerperium) } \\
\text { and at each patient contact with health personnel. When a patient with some complication or emergency is } \\
\text { identified, the critical route for pregnancy surveillance is linked and activated ("Mater Code"). }\end{array}$ \\
\hline Mater Code & $\begin{array}{l}\text { Activation of a mechanism to call the obstetric immediate response team staff to deal with an emergency } \\
\text { and save the lives of the mother and the gestation product. }\end{array}$ \\
\hline
\end{tabular}

Adapted from: Subsecretaría de Prevención y Promoción de la Salud. Lineamiento Técnico $2016^{1}$

reside in the metropolitan area) are initially treated at that medical echelon during pregnancy, delivery and puerperium, and OE and ONE patients who need to continue with their approach by the Obstetric Immediate Response Multidisciplinary Team (OIRMT), composed of expert health personnel of different specialties that are not available at the HMEMYN, are referred to our hospital (Central Military Hospital).

Upon arrival of a patient of these characteristics, categorization of her clinical status is carried out with the obstetric triage scale ${ }^{1}$, in order to assign the degree of priority of her care. In the cases categorized as "Red Code", the institutional protocol known as "Mater Code" is activated in order to alert, bring together and activate the OIRMT, which is made up of medical specialists from the medical and surgical area, as well as residents of the specialty, nurses and administrative support personnel, as established in the technical guidelines "Obstetric Triage, Mater Code and Obstetric Immediate Response Team" (Ministry of Health, 2016) $)^{1,3,5}$.

It was necessary for the institution to implement administrative protocols in order to expeditiously attract (within 30 minutes after the call) the presence of these external specialist physicians to the emergency department, when applicable. On the other hand, patients classified as "Yellow Code" or "Green Code", are managed by their treating physician, with the corresponding procedures established in the Manual of clinical guidelines of the emergency department. When required, the protocol called "Binomial Code" is activated, which is used for the care of pregnant patients who arrive at expulsion phase.

From the record made up by the medical care process, the values corresponding to demographic variables, obstetric triage category, gestational age (weeks of pregnancy), puerperium phase, performed interventions and prognostic indexes (specific complications and mortality) were obtained. Due to the investigative nature of the research, the data of the aforementioned variables were subjected to statistical analysis with centralization and dispersion measures for the descriptive report, in addition to using the relative frequency of occurrence to estimate the proportions corresponding to the study population characteristics.

\section{Results}

During the study period, 48 patients who met the operational criteria to be included in this analysis were admitted to the emergency department of our institution, with an average of 1.4 admissions per month. Average age was $29 \pm 3$ years (range: 17-41). Out of them, eight patients were considered obstetric emergencies (OE, obstetric triage "Red Code"), representing $17 \%$ of cases, and 40 patients (83\%) were categorized as obstetric non-emergencies (ONE, obstetric triage "Yellow Code" and "Green Code") (Fig. 1)1,2.

Of note, the most important cause of admission to the emergency department in our series was postoperative hemorrhage $(n=6,12.5 \%)$, which were cases categorized as genuine OEs and at obstetric triage 
scale "Red Code", followed by threatened abortion and non-serious hypertensive disorders of pregnancy ( $n=5,10.5 \%$ each). The rest of the reasons for admission are described in table 2.

As a particularly important observation for the SWOT analysis and subsequent implementation of improvement actions in our institution, which will be developed in phases II and III of this analysis, it is important to note that 26 patients $(54 \%)$ were referred from external military health facilities or non-institutional health services, and 22 patients (46\%) arrived directly to the hospital, either from their homes or from the street (Fig. 2).

Twenty-four patients arrived pregnant (50\%), with an average gestational age of $16 \pm 4$ weeks (range: 7-39) (Fig. 3). Out of them, five (21\%) arrived at the emergency department during the expulsion phase. After delivery was attended to, these patients were transferred along with the newborn, in good clinical conditions and expeditiously, to the HMEMYN, in order to be followed-up by the corresponding specialty departments. Of note, there was one case of a patient who expelled a 19-week dead fetus immediately upon arrival at the emergency department, with her physical conditions quickly being attended to, since she arrived in a state of hypovolemic shock, and was later transferred to the specialty hospital.

Twenty-four patients (50\%) arrived at their postpartum period (Fig. 3). Twelve patients presented with physiological puerperium and an equal number of cases with surgical puerperium (50\% for both cases). Puerperium mean duration was $2 \pm 0.7$ days (range: $0-4$ ) for those with physiological puerperium and $0.9 \pm 1.9$ days (range: 0-10) for those with surgical puerperium.

Twenty patients $(42 \%)$, including those who were pregnant $(n=5)$, were treated and stabilized at the emergency department to be immediately transferred to the HMEMYN, either by their treating physician or after assessment and treatment by the OIRMT. The most common causes of care for these patients in the emergency department were threatened abortion and non-serious hypertensive disorders of pregnancy (5/48 [10.5\%] each) (Table 2). However, some of them ( $n=28,58 \%$ ) had to remain in the institution to be admitted and subjected to specialized medical-surgical management. The diagnosis that most frequently motivated patient hospital admission was postoperative bleeding ( $n=6 ; 22 \%$ ), followed by serious hypertensive disorders of pregnancy and their complications $(n=5 ; 19 \%$, including three cases of hepatic rupture associated with HELLP syndrome [hemolysis,

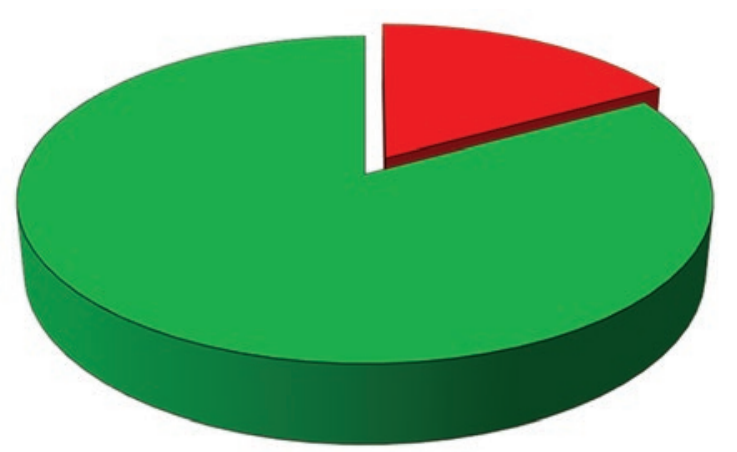

uObstetric emergencies ( $n=8 ; 17 \%)$ 口Obstetric non-emergencies $(n=40 ; 83 \%)$

Figure 1. Distribution of obstetric emergencies and non-emergencies $(N=48)$. (Source: Archivo del Hospital Central Militar, 2017).

Table 2. Causes for admission to the emergency department $(n=48)$

\begin{tabular}{lc}
\hline Cause & $\mathrm{n} / \mathrm{N}(\%)$ \\
\hline Postoperative hemorrhage & $6 / 48(12.5)$ \\
Threatened abortion & $5 / 48(10.5)$ \\
Pregnancy hypertensive disorders (non-serious) & $5 / 48(10.5)$ \\
Pregnancy hypertensive disorders (serious) and their & $5 / 48(10.5)$
\end{tabular}
complications

Urinary infection during pregnancy

$4 / 48$ (8.3)

Low-energy trauma

$3 / 48$ (6.3)

Ectopic pregnancy (ruptured)

$3 / 48$ (6.3)

Ectopic pregnancy (non-ruptured)

2/48 (4.2)

Bile duct lithiasic disease and its

2/48 (4.2)

complications (excluding biliary-origin acute

pancreatitis)

Acute pancreatitis of various etiologies

2/48 (4.2)

Serious, non-surgical sepsis of varied origin

2/48 (4.2)

Postsurgical sepsis

2/48 (4.2)

Acute appendicitis

$1 / 48(2.1)$

Idiopathic pulmonary fibrosis

$1 / 48(2.1)$

Gastrointestinal perforation

$1 / 48(2.1)$

Pulmonary thromboembolism

$1 / 48(2.1)$

Organ failure

$1 / 48(2.1)$

Stroke

$1 / 48(2.1)$

Exacerbation of chronic conditions during pregnancy $\quad 1 / 48(2.1)$ or puerperium

Source: Control de Trabajo Social y Archivos del Departamento de Urgencias, Hospital Central Militar, 2017; Archivo del Hospital Central Militar, 2017.

elevated liver enzymes, low platelet count]), and ruptured ectopic pregnancy ( $n=3 ; 11 \%)$. The remaining causes of admission are shown in table 3 . 


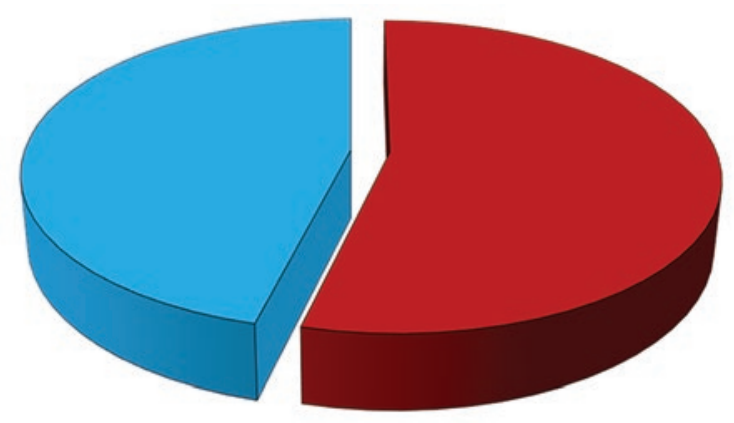

a Referred patients $(n=26 ; 54 \%)$ a Directly-arriving patients $(n=22 ; 46 \%)$

Figure 2. Distribution of patients referred from other health services and directly arriving to the emergency department $(N=48)$. (Source: Archivo del Hospital Central Militar, 2017).

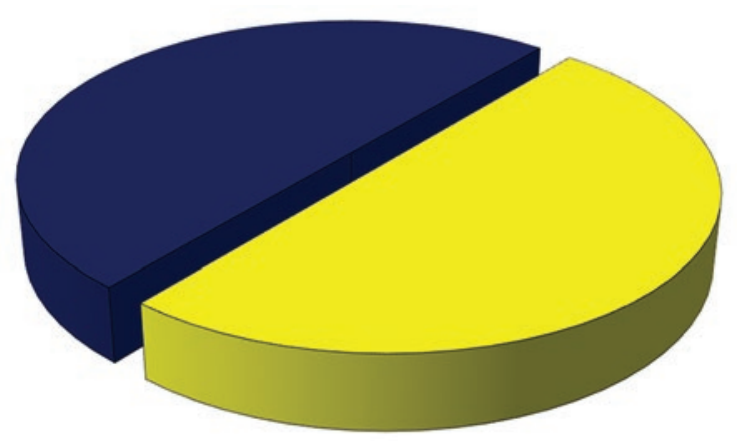

口 Pregnant patients $(n=24 ; 50 \%)$ a Puerperal patients $(n=24 ; 50 \%)$

Figure 3. Distribution of pregnant and puerperal patients $(N=48)$. (Source: Archivo del Hospital Central Militar, 2017).

Based on the above, of the 28 admitted cases, nine were found to have been medically managed $(32 \%)$, while surgical treatment was required in 19 (68\%). The surgical interventions that were most commonly instituted for the management of these cases were surgical hemostasis maneuvers (vascular ligature, electrocoagulation, packing, topical hemostatic agents application), which were required in six cases (31.5\%) of postoperative hemorrhage, followed by exploratory laparotomy for hepatic hemorrhage control and to inhibit bleeding from a ruptured ectopic pregnancy ( $n=3,16 \%$ each) (Table 4). It is important to note that angiography with selective angioembolization, a high-technology resource that is permanently available in our hospital, was performed in five patients as an adjuvant to operative bleeding control.

Due to the severity of their conditions, $82 \%(23 / 28)$ of hospital-admitted patients required comprehensive management at the intensive care unit (ICU). Mean stay of these patients was $6.4 \pm 4.9$ days (range: $2-21$ ). Of the ICU-admitted patients, $35 \%(8 / 23)$ required
Table 3. Causes (diagnoses) of hospital permanence for admission $(n=28)$

\begin{tabular}{lc}
\hline Cause & $\mathrm{n} / \mathrm{n}(\%)$ \\
\hline Postoperative hemorrhage & $6 / 28(21)$ \\
Hypertensive disorders of pregnancy (serious) and their & $5 / 28(18)$ \\
complications & \\
Ruptured ectopic pregnancy & $3 / 28(11)$ \\
Bile duct lithiasic disease and its & $2 / 28(7)$ \\
complications (excluding biliary-origin acute & \\
pancreatitis) & \\
Acute pancreatitis of various etiologies & $2 / 28(7)$ \\
Non-surgical sepsis of varied origin & $2 / 28(7)$ \\
Postsurgical sepsis & $2 / 28(7)$ \\
Acute appendicitis & $1 / 28(3.5)$ \\
Idiopathic pulmonary fibrosis & $1 / 28(3.5)$ \\
Gastrointestinal perforation & $1 / 28(3.5)$ \\
Pulmonary thromboembolism & $1 / 28(3.5)$ \\
Organ failure & $1 / 28(3.5)$ \\
Stroke & $1 / 28(3.5)$ \\
\hline Source: Archivo del Hospital Central Militar, 2017. &
\end{tabular}

mechanical ventilation sometime during their stay. One patient (4\%) with renal failure required renal function replacement therapy. Mean score upon ICU arrival on the APACHE II scale was $19.4 \pm 8.4$ (range: 7-37), which reflects the critical physiological state of the patients managed in said unit and their predicted high probability of death, which in these cases was $35.5 \%$.

Among the complications, the overall morbidity rate in our series reached $27 \%$ (13/48), with 24 specific complications being found, for a mean of 1.8 specific complications per patient. For the purposes of this study, we believe that the most important are those related to septic complications, organ failure (mainly respiratory and renal), coagulopathy, thromboembolic phenomena and neurological accidents, and their stratification was therefore based on this reasoning. On this basis, kidney failure was the most common specific complication, occurring in $46 \%(6 / 13)$ of patients with complications, followed by coagulopathy and pulmonary-origin sepsis (38.5\%; 5/13). The distribution of the rest of specific morbidities is described in Table 5.

Overall mortality rate was $6.2 \%$. Specific mortality for the group of pregnant patients was $0 \%(0 / 24)$, whereas for the group of puerperal patients it was $12.5 \%(3 / 24)$. One puerperal patient died in the 
Table 4. Operative strategies for the treatment of patients undergoing surgical treatment $(n=19)$

\begin{tabular}{lc}
\hline Operative strategy* & $\mathrm{n} / \mathbf{n}(\%)$ \\
\hline $\begin{array}{l}\text { Surgical hemostasis (vascular ligature, } \\
\text { electrocoagulation, packing and topical hemostatic }\end{array}$ & $6 / 19(31.5)$ \\
$\begin{array}{l}\text { agents application) } \\
\text { Exploratory laparotomy with hepatostasis }\end{array}$ & $3 / 19(16)$ \\
$\begin{array}{l}\text { Exploratory laparotomy to inhibit bleeding from ruptured } \\
\text { ectopic pregnancy }\end{array}$ & $3 / 19(16)$ \\
$\begin{array}{l}\text { Surgical cleaning (sequential), control of sepsis source } \\
\text { and management with open abdomen }\end{array}$ & $3 / 19(16)$ \\
$\begin{array}{l}\text { Laparoscopic cholecystectomy } \\
\text { Laparoscopic appendectomy }\end{array}$ & $2 / 19(11)$ \\
$\begin{array}{l}\text { Thoracotomy at the emergency department, with open } \\
\text { chest and abdomen management }\end{array}$ & $1 / 19(5)$ \\
\hline
\end{tabular}

${ }^{*}$ Angiography with selective angioembolization was employed in five patients as an adjuvant to operative bleeding control.

Source: Archivo del Hospital Central Militar, 2017.

Table 5. Specific mortality distribution $(n=13)$

Type of complication* Specific complication ( $\mathrm{n} / \mathrm{n} ; \%)$

Septic complications Pulmonary sepsis $(5 / 13 ; 38.5)$

Persistent abdominal sepsis $(3 / 13 ; 23)$

Organ failure $\quad$ Kidney failure $(6 / 13 ; 46)$

Liver failure $(2 / 13 ; 15.5)$

Heart failure $(1 / 13 ; 8)$

Coagulopathy Coagulopathy associated with pregnancy or puerperium $(5 / 13 ; 38.5)$

Neurological accidents Ischemic stroke $(1 / 13 ; 8)$

Others Lethal arrhythmia $(1 / 13 ; 8)$

*No thromboembolic complications were found, although this phenomenon was the cause of death of one puerperal patient at the emergency department.

Source: Archivo del Hospital Central Militar, 2017.

emergency department due to massive pulmonary thromboembolism, while another, also in her puerperium, succumbed in the regular hospitalization unit due to idiopathic interstitial pneumonitis at fibrotic stage. One patient with peritoneal tuberculosis and uncontrollable abdominal sepsis died at the ICU, for a specific mortality rate of $4.3 \%$ in this unit $(1 / 23)$.

\section{Discussion}

Owing to its impact on national economy and on societal moral and growth, maternal health is a healthcare area of the highest interest for any country. In Mexico, the incidence and prevalence of maternal complications and deaths have forced government authorities and nongovernmental organizations to institute measures at different levels of social order to mitigate the above-mentioned serious effects ${ }^{1-5}$.

As a reflection of the policies to increase the quality and safety of patient medical attention, at the Central Military Hospital, actions aimed at optimizing the various medical-surgical care procedures for $\mathrm{OE}$ and ONE have increased since 2012. In addition, the interest of the institution's high authorities to promote professional competence and the recent modernization of the emergency department facilities have enabled to efficiently address cardiovascular diseases and coagulopathies, as well as to approach the patient during childbirth or medical abortion in an area specially designated for this purpose and with a specialized protocol ("Binomial code"). Therefore, we believe that all the above potentially contributes to increase survival in these cases and to decrease the incidence and prevalence of complications, especially those of a coagulopathic nature, thromboembolic phenomena, neurological accidents and organ failure. This study shows the experience that, making use of these human, material and administrative resources, the institution has gained, positioning itself as a model hospital regarding the care of critical patients, including OE and ONE cases.

Even when most emergency department admissions are cases of postoperative hemorrhage categorized with obstetric triage scale "Red Code" $(n=6$; $12.5 \%)$, notably, $83 \%(n=40)$ of obstetric cases attended to in our hospital were not OEs. However, several of them, classified as ONEs, represent a population that benefits from a timely care system, delineated by the scales and priority allocation procedures for the medical care services available in the institution (Table 2). Most ONEs are cases of threatened abortion and non-severe hypertensive disorders of pregnancy, which are clinical conditions that are suitable for the implementation of diagnostic and therapeutic approaches by medical specialists and successful use of the corresponding specific protocols for the conditions in question, which are established in the departmental manuals, and later defining their hospital stay or referral to the obstetric-gynecological specialty hospital.

On the other hand, OE, as operationally defined in the institution, fortunately occurred in a lower percentage of cases $(17 \% ; n=8)^{1,2,6-8}$. In these situations, for its adequate approach, the protocol called "Mater Code"1,2,4-7 is activated at the emergency department, which in turn alerts, brings together and sets the OIRMT elements in motion. The various members of 
this team proceed to look after the patient according to the procedure that is applicable to the specific condition she arrives with, requesting, by means of special administrative regulations, the intervention of obstetrics-gynecology and pediatrics specialists belonging to HMEMYN, which is a facility near our hospital, with them arriving within the next 20 minutes after the call. When the nature of the "Mater Code" protocol activation indications were stratified, we found that the conditions that most often motivate it are cases of postoperative hemorrhage and serious hypertensive disorders of pregnancy and their complications, which enables that, after adequate cardiologic and neurological assessment and treatment in regular hospitalization or even in intensive cardiovascular care units, patients can be referred to the corresponding specialty center with marked improvement in their physical conditions. Unfortunately, in these specific cases, surgical specialists' intervention has also been required, specifically for the treatment of three patients with HELLP-related hepatic rupture. Due to its permanent availability in our hospital, practicing angiography with selective angioembolization was also possible in these three patients as an adjunctive method to surgical hepatostasis.

One patient with immediate surgical puerperium and exsanguinating coagulopathic bleeding who was transferred from the HMEMYN, had a thoracotomy practiced at the emergency department with excellent results for life and neurological function, which represents a remarkable achievement for our institution and with no doubt constitutes a national benchmark for the practice of the procedure, since the reports on its use in non-traumatic cardiac arrest are anecdotal ${ }^{8,9}$. Moreover, it reflects the great potential of the human and material resources of our hospital for the care of obstetric patients in extremis.

The overall complication rate found in our series was $27 \%(n=13)$, with the most common being kidney failure $(6 / 13,46 \%)$, pulmonary-origin sepsis and coagulopathy $(5 / 13,38.5 \%)$, which are specific conditions that have been reported in the literature as those that occur most frequently in cases of morbidity ${ }^{10-14}$. This contrasts with observations reported for general hospitals, where the overall morbidity rate is $6-21 \%$. We consider that this phenomenon is fundamentally due to the fact that several referred patients arrive in anatomical and physiological conditions of high severity, presenting with complications that were in fact already computed for our analysis and showing a torpid clinical evolution, which further increased the morbidity rate.
Overall mortality in our series was $6.2 \%$ (3/48). One puerperal patient with idiopathic interstitial lung disease at fibrotic stage died in the regular hospitalization unit, and another, also in her puerperium, succumbed with massive pulmonary thromboembolism at the emergency department, for a mortality of $4.1 \%(2 / 48)$ outside the ICU. However, to analyze this issue in greater depth, it is necessary to emphasize on the large proportion of patients who met the criteria for ICU admission (23/48, 48\%). As previously mentioned, the high APACHE II score these patients arrived with, which reached the order of 19.4 in the corresponding scale, was related to a predicted high possibility of death (35.5\%). Hazelgrove et $\mathrm{al}^{10}$, in a multicenter study of obstetric admissions to 14 intensive care units $(N=210)$, which perhaps represents the largest specific series reported in the literature, found a maternal mortality rate of $3.3 \%$, with causes of death being defined as shock status of various origins and cardiovascular diseases. Clearly, in spite of the statistical correlation between the APACHE II score and predicted mortality, the overall mortality rate in the ICU was lower than expected and than the mean rate indicated by the world literature $(15 \%$, range: $1-33 \%)^{10-14}$. This, in addition to the reduced sample size, may reflect the opportunity for protocol-based care being provided to these patients since their very stay at emergency department. Moreover, the ICU has the necessary human and material resources (with slow continuous renal replacement therapy standing out) that as a whole are essential to avoid interrupting the timely and highly specialized care required by these patients.

By virtue of not having the possibility of following the newborns up, we are aware that this study lacks the necessary power to analyze the clinical evolution of the mother-child binomial, which is an important factor in determining the timeliness, quality and safety of the medical-surgical care provided to the mother, since the newborn's prognostic indexes are an indisputable reflection of that which has been previously pointed out.

In conclusion, as a consequence of the position of the Federal Government and the interested Government Agencies, as well as of the military authorities, the Central Military Hospital has delineated and defined various procedures to reduce maternal morbidity and mortality. We have the reasonable certainty that the correct practice of these procedures and close collaboration with the HMEMYN will contribute to achieving the desired institutional goals, and help 
covering the priorities related to maternal health as stipulated in the National Health Policy ${ }^{3}$.

\section{Acknowledgements}

We thank Major Óscar Enrique Pérez-Morales, MD, and Major Gabriela Alhelí Guillén Hernández, MD, for their statistical collaboration and co-authorship in this study.

\section{Conflicts of interest}

The authors declare not having any conflicts of interest.

\section{References}

1. Subsecretaría de Prevención y Promoción de la Salud. Lineamiento Técnico 2016 "Triage Obstétrico, Código Máter y Equipo de Respuesta Inmediata Obstétrica". Ciudad de México (México): Secretaría de Salud 2016. 60 p. (Consultado el 20 de diciembre de 2017.) Disponible en: https://www.gob.mx/cms/uploads/attachment/file/270472/web_TriageObstetricoCM.pdf

2. Salinas AA, Villegas JM. Guía técnica para el funcionamiento del Código Máter en las unidades hospitalarias de segundo nivel de atención médica del Instituto de Salud del Estado de México. Toluca (Estado de México): Instituto de Salud del Estado de México; 2009. 13 p. (Consultado el 21 de diciembre de 2017.) Disponible en: https://es.scribd.com/doc/66530700/ Guia-Tecnica-Para-El-Codigo-Mater-en-Unidades-Hospital-Arias

3. Subsecretaría de Prevención y Promoción de la Salud. Salud materna Ciudad de México (México): Secretaría de Salud; 2015. 39 p. (Consultado el
21 de diciembre de 2017.) Disponible en: http://www.senado.gob.mx/comisiones/igualdad_genero/reu/docs/presentacion_170615_1.pdf

4. Diario Oficial de la Federación. Norma Oficial Mexicana NOM-007SSA2-2016 para la atención de la mujer durante el embarazo, parto y puerperio, y de la persona recién nacida. Ciudad de México (México): Secretaría de Gobernación; 2016. 22 p. (Consultado el 20 de diciembre de 2017.) Disponible en: http://www.dof.gob.mx/nota_detalle.php?codigo $=5432289 \&$ fecha $=07 / 04 / 2016$

5. Alvarado BRM, Arroyo VM, Hernández PC, Vélez CM, Márquez TP Manejo del triage obstétrico y código máter en el Estado de México. Enfermería Universitaria. 2012;9:61-71.

6. Fescina R, De Mucio B, Ortiz El, Jarquin D. Guía para la atención de las principales emergencias obstétricas. Montevideo (Uruguay): Organización Panamericana de la Salud; 2012. 76 p. (Consultado el 20 de diciembre de 2017.) Disponible en: http://www.paho.org/clap/index. php? option=com_docman\&view=download\&category_slug=salud-de-mujer-reproductiva-materna-y-perinatal\&alias=279-guias-para-la-atencion-de-las-principales-emergencias-obstetricas-1\& Itemid=219\&lang=es

7. Briones GJC, Gutiérrez VMC, Esquivel GLJ, de León PM, Briones VCG. Experiencia exitosa con el Código Máter. Med Crit Ter Int. 2011:25:43-5.

8. Committee on Obstetric Practice and the American Academy of Pediatrics' Council Environmental Health. Committee opinion no. 726: Hospital disaster preparedness for obstetricians and facilities providing maternity care. Obstet Gynecol. 2017:130:291-7.

9. Kornhall DK, Dolven T. Resuscitative thoracotomies and open chest cardiac compressions in non-traumatic cardiac arrest. World J Emerg Surg. 2014:9:54-9.

10. Hazelgrove JF, Price C, Pappachan VJ, Smith GB. Multicenter study of obstetric admissions to 14 intensive care units in Southern England. Crit Care Med. 2001:29:770-5.

11. Anwari JS, Butt AA, Al-Dar MA. Obstetric admissions to the intensive care unit. Saudi Med J. 2004;25:1394-9.

12. Okafor UV, Aniebue U. Admission pattern and outcome in critical care obstetric patients. Int J Obstet Anesth. 2004;13:164-6.

13. Hasbún HJ, Sepúlveda-Martínez A, Cornejo RR, Romero PC. Intensive care admissions due to severe maternal morbidity. Rev Med Chil. 2013; 141:1512-9.

14. Thakur M, Gonik B, Gill N, Awonuga AO, Rocha FG, González JM. Intensive care admissions in pregnancy: analysis of a level of support scoring system. Matern Child Health J. 2016;20:106-13. 